\title{
RHEUMATOID LUNG CHANGES ASSOCIATED WITH ASBESTOSIS
}

\author{
BY \\ ANTHONY G. RICKARDS AND GEOFFREY M. BARRETT \\ From the Departments of Pathology and Medicine, Royal Infirmary, Lancaster
}

(RECEIVED FOR PUBLICATION JANUARY 8, 1958)

The development of a peculiar form of pneumonitis in cases of acute rheumatism was described by Latham in 1845 , but a century passed before the publication of the first reports of pulmonary involvement in rheumatoid arthritis. Since the papers of Ellman (1947) and Ellman and Ball (1948) there have been many other reports of lung changes associated with rheumatoid arthritis: in some the nature of the lung disease has been determined at necropsy or by biopsy, but often the lung involvement has only been demonstrated radiologically. In the special field of pneumoconiosis radiological studies led to Caplan's recognition (1953) of a modification in the pattern of anthraco-silicosis when coal-miners developed rheumatoid arthritis. Gough, Rivers, and Seal (1955) showed histologically that the essential difference between the orthodox pneumoconiotic nodules and the Caplan nodules was the presence in the latter of an inflammatory reaction of rheumatoid type.

These observations of Caplan and of Gough and his colleagues are not only of interest to workers in dust diseases, but raise issues of immediate importance to the understanding of the basic inflammatory response in rheumatoid arthritis.

We have recently had under our care a middleaged man who developed severe rheumatoid disease which was associated with widespread pulmonary fibrosis. Necropsy revealed in the lungs numerous necrobiotic foci of rheumatoid type superimposed upon extensive pulmonary asbestosis. This is the first case of this sort recorded.

\section{CASe Report}

When first seen by one of us (G. M. B.) in October, 1956, the patient, a 49-year-old man, had been complaining of joint pains for 10 months. His symptoms had begun suddenly in the shoulder region, and initially were attributed to a radiologically demonstrated cervical spondylosis, but by May, 1956, joint pains had become more generalized and subcutaneous nodules had appeared in the region of the right elbow. Two estimations of the erythrocyte sedimentation rate (E.S.R.) had shown figures of 34 and $36 \mathrm{~mm}$. in one hour (Wintrobe method), and an orthochromic anaemia with a haemoglobin of $10.2 \mathrm{~g}$. per $100 \mathrm{ml}$. had been demonstrated. Radiographs of a number of large joints had shown no abnormality. but no films had been taken of the hands or feet. A radiograph of the chest was reported to show loss of translucency affecting the middle and lower zones on both sides, with an exaggeration of the lung pattern indicative of fibrotic change (Fig. 1). The patient had been treated with calcium aspirin, and when seen in October stated that the joint pains were improved but he was less well in himself and had lost $16 \mathrm{lb}$. $(7.3 \mathrm{~kg}$.) in weight during the previous 18 months. The diagnosis of rheumatoid arthritis was clinically acceptable, there being thickening of a number of interphalangeal joints, some excess of synovial fluid in both knee joints, and subcutaneous nodules of rheumatoid type near the right elbow. No abnormal signs were detected in the cardiovascular or respiratory systems ; there was no significant enlargement of superficial lymph nodes and neither the spleen nor the liver was palpable. The E.S.R. was again found to be $34 \mathrm{~mm}$. in one hour and continuation of calcium aspirin therapy was advised.

On November 14, 1956, the patient was sent into hospital as an emergency with a diagnosis of acute bronchitis. He looked acutely ill, showed appreciably more general muscle wasting than had been present previously and more obvious joint changes of rheumatoid disease. There was no rise in the respiration rate at rest, but he had a loose cough productive of mucopurulent sputum, and fine moist sounds were audible at both lung bases: the temperature was $100^{\circ} \mathrm{F}$., and a blood count showed a moderate polymorphonuclear leucocytosis. Tachycardia was in keeping with the degree of pyrexia, the blood pressure was $120 / 60 \mathrm{~mm}$. $\mathrm{Hg}$, and there was no evidence of primary cardiac disease. Intensive treatment with antibiotics was begun. Although this was followed by a fall in temperature, the pulse rate rose steadily, and five days after admission the patient died in peripheral circulatory failure attributed to influenzal pneumonia. 


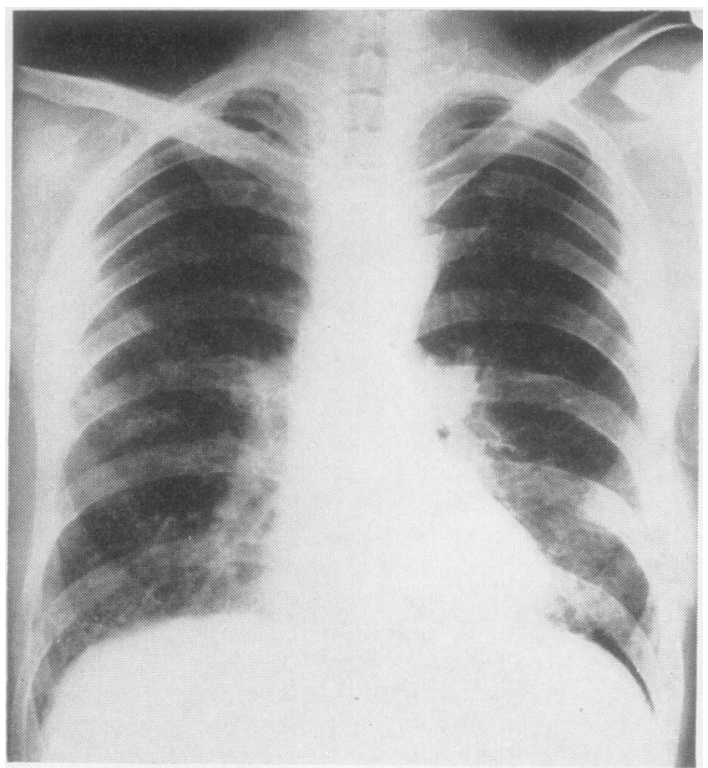

Fig. 1.-Chest radiograph taken six months before death showing mid and lower zone mottling.

Subsequent inquiry showed that the patient had served during the second world war in the Royal Navy, having been a fit athletic individual; on demobilization he had worked in various places as a general labourer and had been employed in that capacity in an asbestos factory from January, 1952, to January, 1956, when he had first reported sick. In this factory diatomaceous earth obtained from a local deposit was extracted, calcined, mixed with asbestos in proportions varying from 5 to $30 \%$, and bagged for dispatch to other works in the group. The patient as a "spare hand" had worked on virtually every job in the factory, and our own observations indicate that he must have been exposed to a very high concentration of dust whenever he was on indoor duties. Face masks were provided for indoor workers, but were being worn by only one man on the occasion when we visited the factory.

Necropsy was carried out nine hours after death. The body was that of a frail, middle-aged man looking older than his years; the arms and legs were markedly wasted and the knee-joints were slightly swollen, but no gross rheumatoid deformities of the other joints were visible. Both elbow regions showed many subcutaneous nodules of typical rheumatoid type.

The thoracic cavities both contained a large amount of fluid, and heavy fibrin deposits were present over the visceral pleural surfaces; microscopic study showed no bacteria and the fluid was sterile on aerobic and anaerobic culture. The effusion was not loculated and there were no adhesions. The main pathological features were found in the lungs, both of which showed very similar appearances; they were unusually firm and rubbery in consistency and were much heavier than normal, weighing 850 and $900 \mathrm{~g}$. each. The naked-eye appearances suggested a diffuse interstitial pneumonitis involving all areas, but in the lower and middle zones of both lungs numerous breaking down abscesses of unusual appearance were found. These were grey in colour and nodular in form, and were distributed widely throughout the middle and lower lobes but were most plentiful towards the periphery of the lungs, some of them being situated within a centimetre of the pleural surface ; they varied from pin-head size to a maximum of $1.5 \mathrm{~cm}$. in diameter. At the necropsy they were considered to be probably of tuberculous origin. Prominent also in the lower and middle zones were streaks of fine reticular fibrosis. The trachea and main bronchi were free from pus. The mediastinal lymph nodes were not enlarged. The heart, which weighed 300 g., showed hypertrophy and dilatation of the right ventricle and atrium, but was otherwise normal. The liver showed moderate centrilobular congestion and the spleen appeared normal, weighing $160 \mathrm{~g}$. Full examination of all other organs, including brain. showed no further pathological features.

Sections were stained by haematoxylin and eosin and by Perls's, Mallory's trichrome, Laidlaw's reticulin, and Ziehl-Neelsen's methods. Microscopic examination of the lung showed generalized asbestosis with a diffuse interstitial pneumonitis. In addition there was diffuse fibrosis especially marked in the middlo zones. The middle and lower zone abscesses prove to be typical necrobiotic foci of rheumatoid diseas (Figs. 2 and 3). All parts of the lungs showe numerous collections of asbestosis bodies in varying stages of development ; many of the bodies were fully developed with a well-marked haemosiderin-protein covering whereas others appeared to have remained quite unchanged, consisting of needle-like fibres of asbestos which remained unstained after treatment with potassium ferrocyanide and hydrochloric acid (Perls's stain). Many of these bodies were lying free in the alveoli but others were partially or completely engulfed by large giant cells lying freely within the alveolar spaces (Fig. 4). Associated with the giant cells were numerous intra-alveolar histiocytes from which the former cells appeared to have been derived; while these intra-alveolar collections of cells differed in intensity from area to area, no alveolus was entirely free from infiltration and very many air spaces must have been rendered functionally useless by the cell accumulations (Fig. 5): in several areas numerous plasma cells and lymphocytes were intimately admixed with the histiocytes and giant cells ; in many spaces the alveolar reaction was essentially fibroblastic in nature and spindlecelled fibroblasts were sometimes arranged around the periphery of the alveolus in a rough palisade pattern (Fig. 6). The alveolar septa were everywhere greatly thickened and distorted by a well-developed histiocytic proliferation associated with an infiltration of plasma cells and lymphocytes. In the middle and lower zones of the lungs the general pattern of the 
(3)

\section{FIG. 2.-Area of rheumatoid necrobiosis in lung. Haematoxylin and eosin. $\times 100$.}

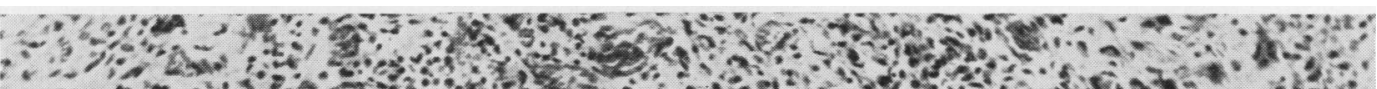
3.0.

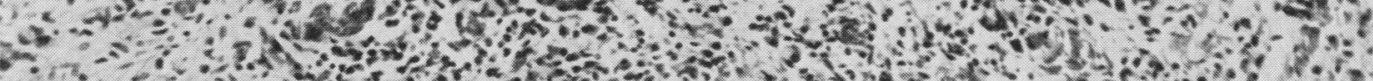

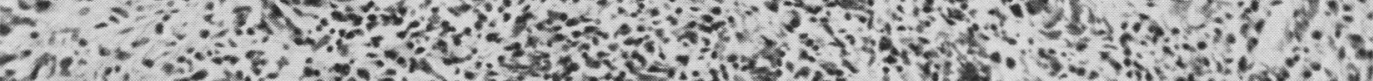
-3at

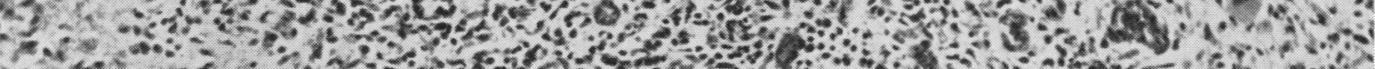

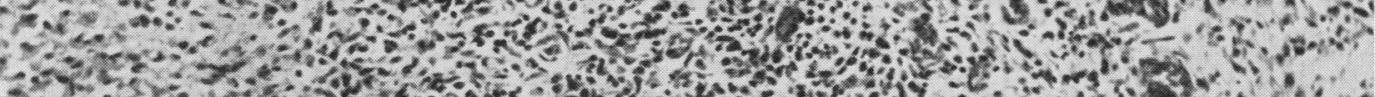

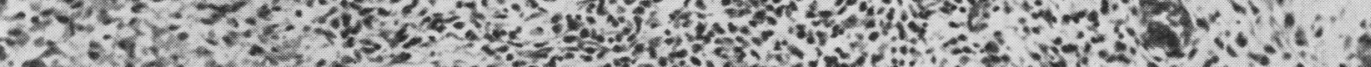

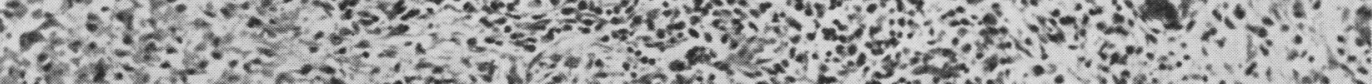

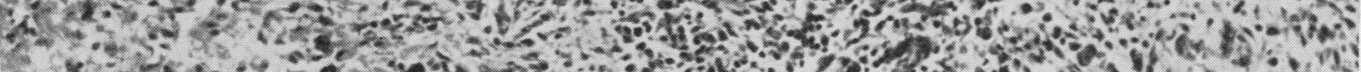

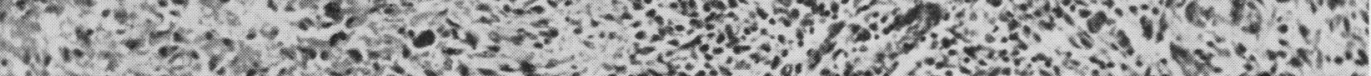

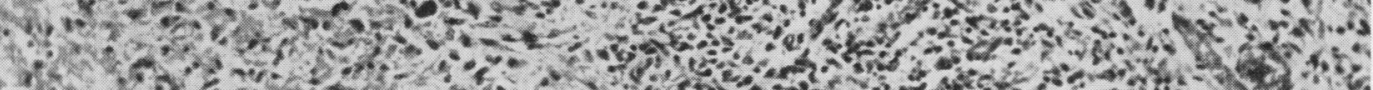

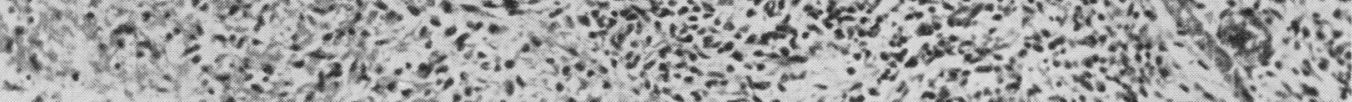
a

FIG. 3.-Periphery of necrobiotic lesion showing fibroplastic proliferation rich in newly formed capillaries. Haematoxylin and eosin. $\times 100$. 


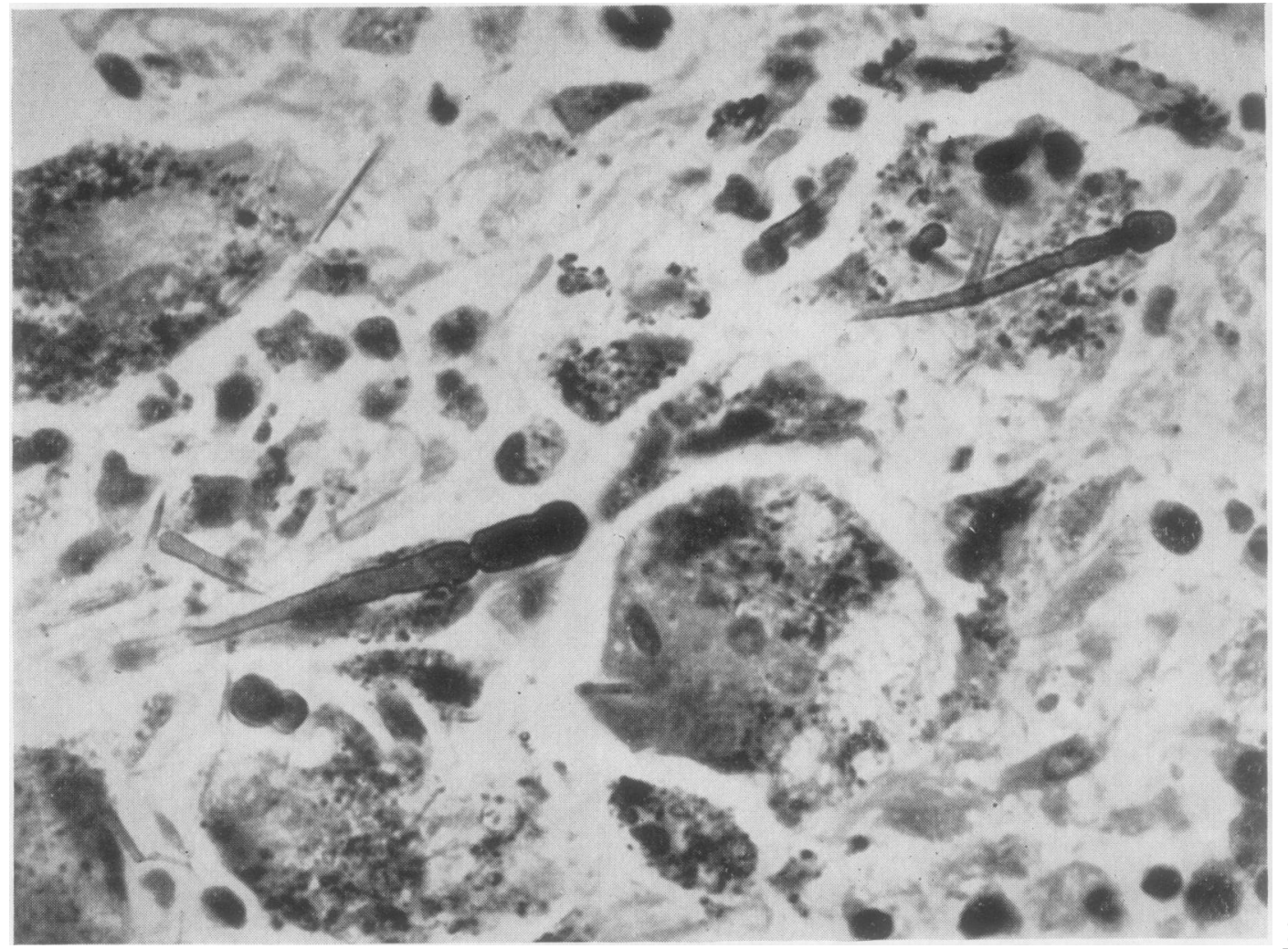

FIG. 4.-Asbestosis bodies in various stages of development, some engulfed by giant cells. Haematoxylin and eosin. $\times 700$. Fit.

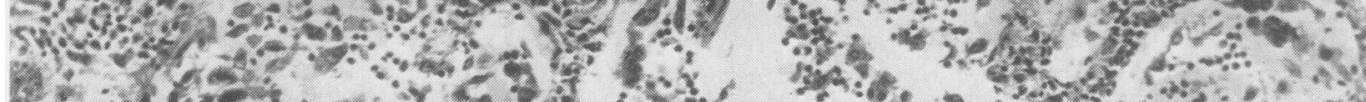
2.

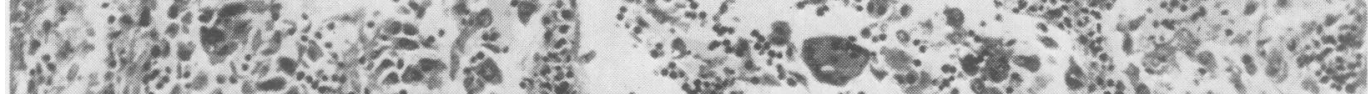

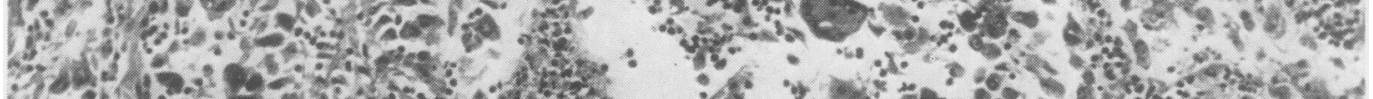

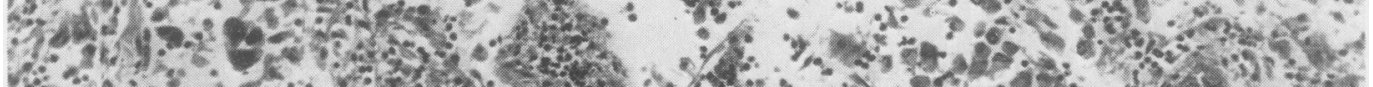
- 2.

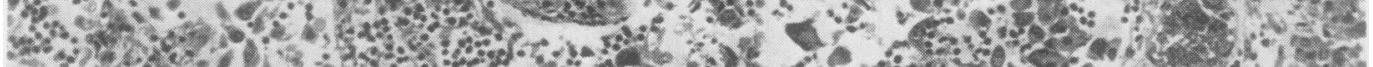

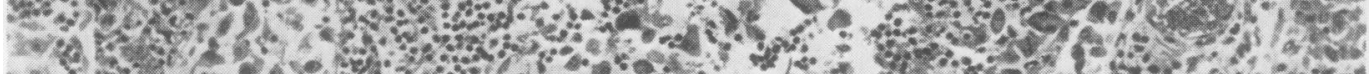

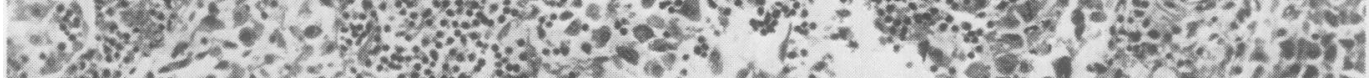

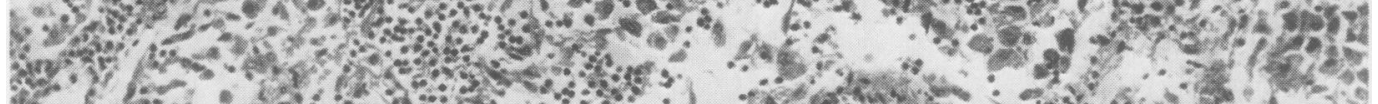

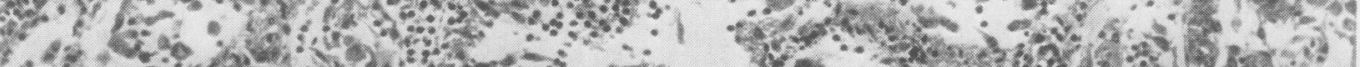

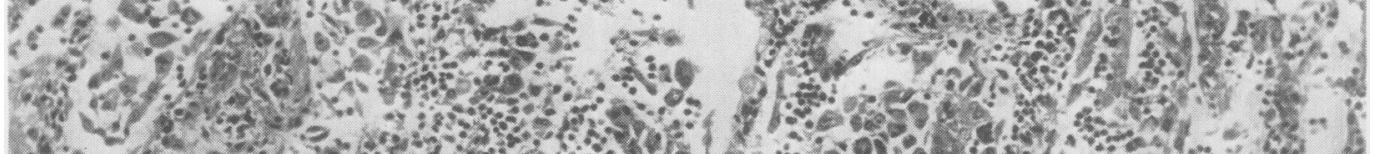

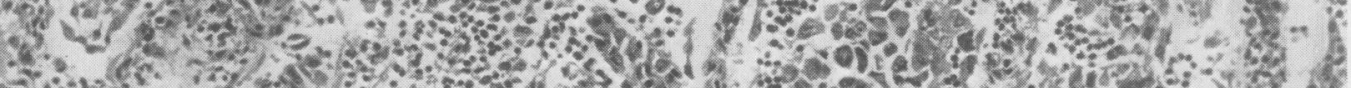

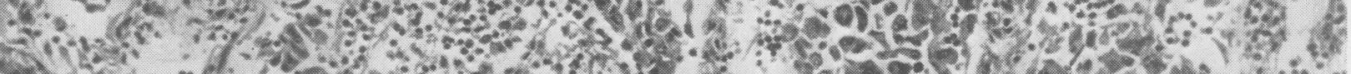
C.

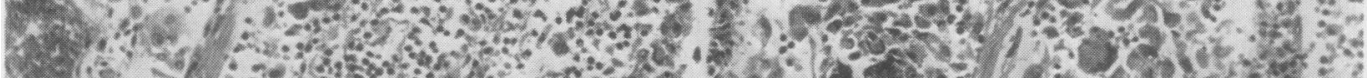
8.

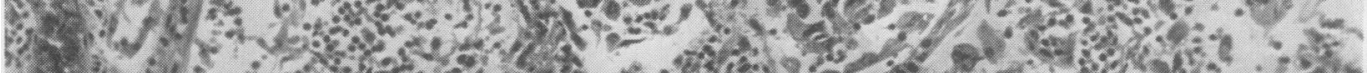

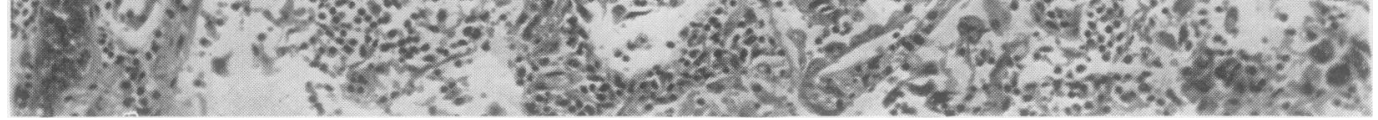

FIG. 5.-Diffuse pneumonitis with alveoli occupied by histiocytes, plasma cells, lymphocytes, and giant cells. Haematoxylin and eosin. 


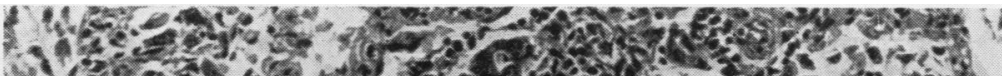

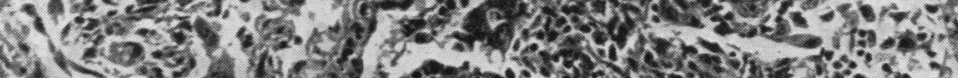

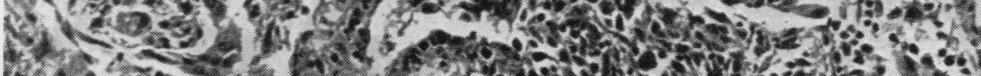

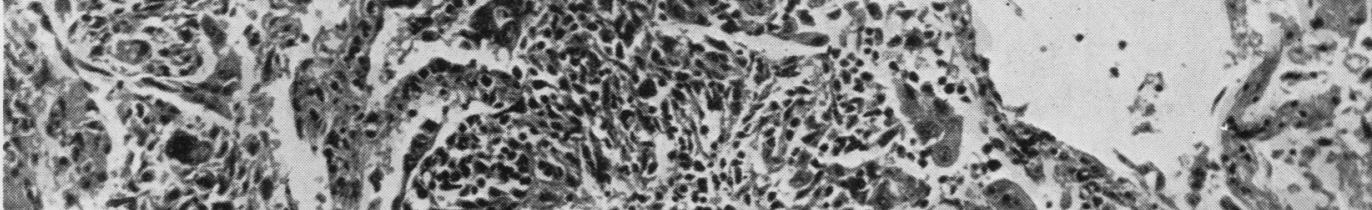

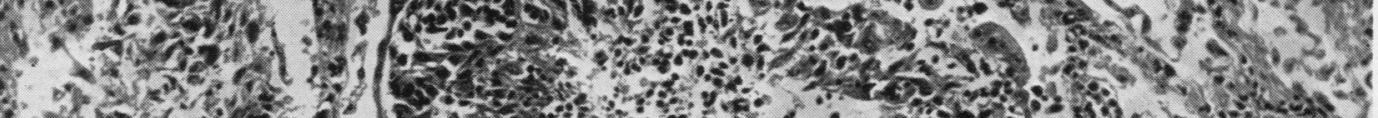

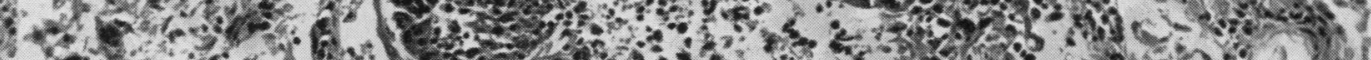

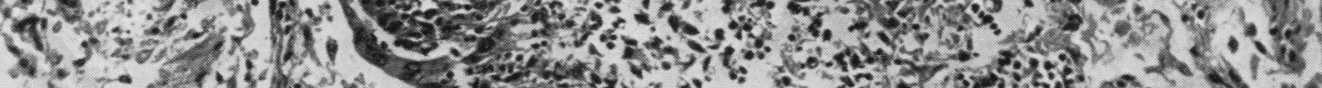

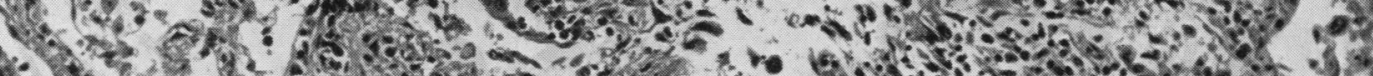

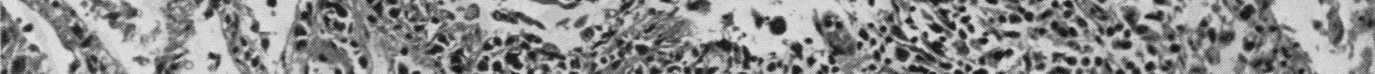

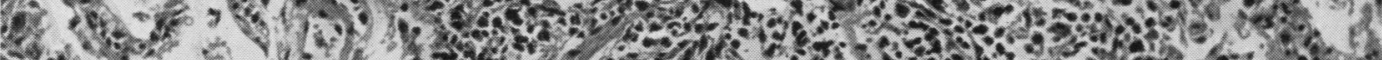

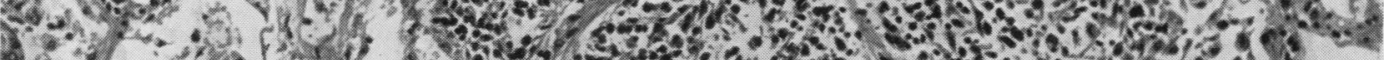

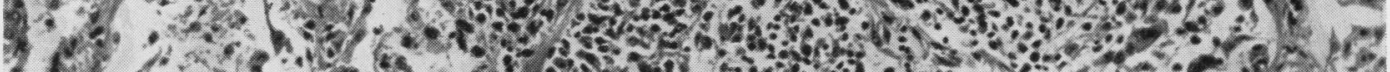

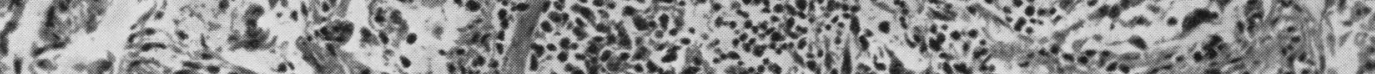

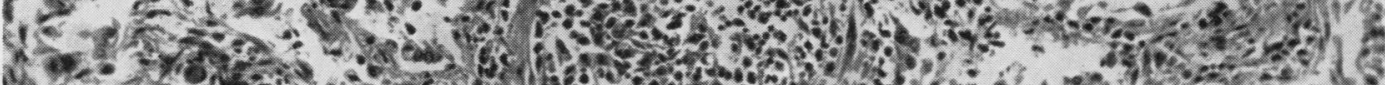

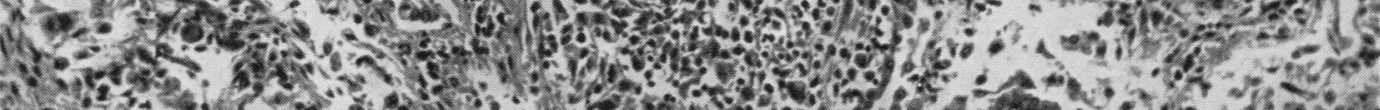
If

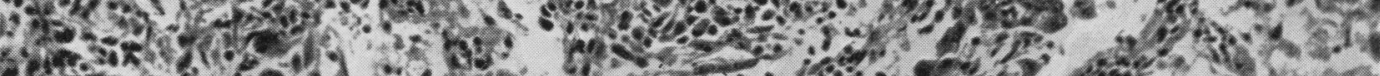

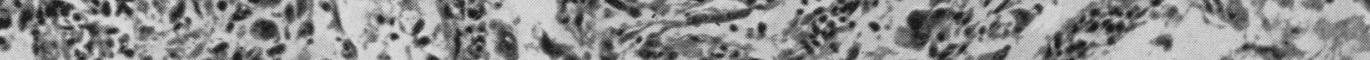

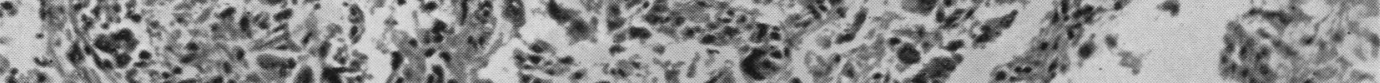
c.; FIG. 6.-Alveoli containing fibroblasts and histiocytes arranged in rough palisade formation.

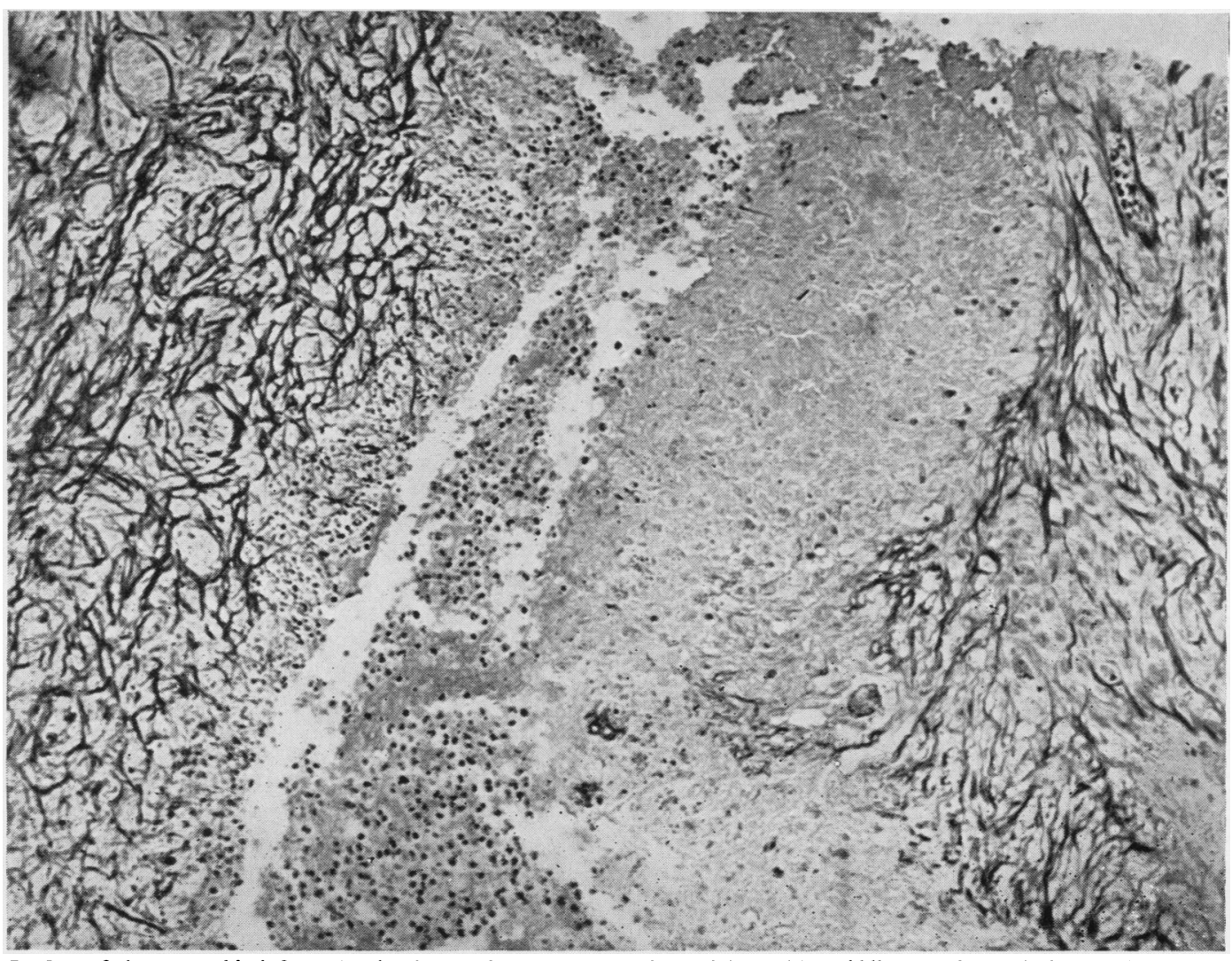

FIG. 7.-Part of a large nocrobiotic focus showing denso reticulin in centre and at periphery with a middle zone of nocrotic tissue. Laidlaw. $\times 100$ 
inflammatory response was altered by the presence of areas of older fibrosis in which many asbestos particles were present; plasma cells and lymphocytes were plentiful. Although necrobiotic rheumatoid foci were found on microscopic examination of the upper lobes these were much smaller and less frequent than those in the middle and lower lobes. The distribution of rheumatoid necrobiotic foci accords closely with the pattern of pulmonary fibrosis ordinarily encountered in asbestos pneumoconiosis and was clearly demonstrated in the first chest radiographs taken several months before death. In the peripheral parts of the necrotic zone the usual eosinophilic staining gave place to a speckled haematoxyphilic zone probably due to the peripheral accumulations of nuclear debris derived from migratory inflammatory cells, such as occurs around bland infarcts which are five to six days old. The centres of some of the necrotic areas showed tightly packed collagen bundles (Fig. 7), but others were more amorphous although, except for the smallest lesions, occasional collagen and reticulin fibres could usually be discerned. Within the areas of necrosis could still be seen numerous particles of asbestos fibre in various stages of development from apparently unchanged needle forms to the fully developed asbestosis body. The distribution of these bodies was not noticeably different from that in the surrounding lung tissue, suggesting that the necrobiotic lesions were of relatively recent occurrence and not much older than nine months, this being the interval between death and last exposure to dust. Study of the pulmonary and bronchial vessels showed no significant lesions.

\section{Discussion}

Since the original reports of Ellman (1947) and Ellman and Ball (1948) a further 53 cases of pulmonary disease in rheumatoid arthritis have been described (references to which will be found in an addendum). In 15 of these cases the lesions have been associated with silicosis (Colinet, 1950, 1953 ; Gough and others, 1955 ; Martin and Fallet, 1953 ; Miall, Caplan, Cochrane, Kilpatrick, and Oldham, 1953 ; Tara, Cavigneaux, and Delplace, 1954 ; van der Meer, 1954), whilst in the remaining cases there has been no evidence of previous exposure to dust particles. Among these cases are several in which the diagnosis of rheumatoid lung is based on clinical and radiological evidence only, but in others the diagnosis has been established by pathological examination of the lungs either by biopsy or at necropsy. Broadly speaking, in 11 of the cases where pathological study has been undertaken, the lesion has consisted of a nonspecific fibrosing pneumonitis whilst in the remaining 26 cases the lung pathology has consisted of necrobiotic foci of typical rheumatoid type, bearing a close histological resemblance to the more familiar subcutaneous rheumatoid nodules which occur so frequently in the region of the elbow joint. Among this latter group of 26 cases, in no fewer than 15 has there been an association with pneumoconiosis; among the remaining 11 cases of uncomplicated necrobiotic pulmonary lesions within this group necropsy has revealed a remarkably widespread dissemination of these nodules in extrapulmonary tissues, and in no case have the necrobiotic lesions been confined to the lung. After the lung, the organ most frequently involved has been the heart (seven cases), although lesions have been described in dura mater, the walls of arteries, striped muscle, larynx, peritoneum, kidney, lymph nodes, and spleen. It may be permitted here to anticipate our description of the lesions in the pneumoconiotic group by emphasizing that this widespread dissemination of lesions in extrapulmonary tissues contrasts sharply with the distribution within the pneumoconiotic group where, apart from subcutaneous lesions, the granulomata have been confined to the lungs.

The recognition of the existence of the pneumoconiotic form of rheumatoid lung dates from the observation of Caplan (1953) that miners with coal-workers' pneumoconiosis who develope rheumatoid arthritis often showed a distinctive pattern in the chest radiograph, consisting of multiple, well-defined round opacities distributeđ throughout both lung fields but particularly marked at the periphery. This appearance was in marked contrast to the radiographic pattern of massive pneumoconiotic nodules ordinarily encountered in coal-workers, in which the opacities are not so well defined, tend to be larger and more irregular in outline, and usually number only one or two in each lung field. A further important observation was that the rheumatoid nodules often occurred when the background of simple pneumoconiosis was slight, or even absent, whereas the massive nodules of coal-workers' pneumoconiosis occur only against a background of severe diffuse simple pneumoconiosis.

In a careful epidemiological study of the Caplan syndrome Miall and others (1953) confirmed the observation that a particular type of radiographic 0 appearance in the lungs of coal-miners was closely $\tilde{O}$ associated with the presence of rheumatoid arthri- N tis, and found that the prevalence of rheumatoid disease among cases showing the characteristic 0 radiographic pattern was over $50 \%$; the diagnosis $\stackrel{\odot}{\leftarrow}$ of rheumatoid arthritis could have been made $\stackrel{\mathcal{O}}{?}$ from the chest radiographs alone with more than 0 a $50 \%$ chance of being correct. These authors 
were the first to describe in some detail the pathological findings in an elderly man showing clinical and radiological evidence of the Caplan syndrome who died in congestive cardiac failure. The lesions in this case, however, showed little evidence of activity, and it was not until 1955 that the pathological features were first clearly described by Gough and others (1955), who gave a detailed account of 14 necropsy and two biopsy studies of coal-workers with rheumatoid arthritis. In no less than seven of the 16 cases chest radiographs had shown the typical rheumatoid opacities, and although the histological features were complicated by the presence of nodular pneumoconiosis and sometimes further complicated by the coexistence of tuberculosis, it was clear that the essential difference between the orthodox pneumoconiotic nodule and the Caplan nodule was the presence in the latter of an inflammatory reaction exhibiting striking histological resemblances to the more commonly encountered subcutaneous rheumatoid nodules. Apart from the cases reported by the Cardiff workers a further acceptable case of modified pneumoconiosis in a sand blaster has been recorded by van der Meer (1954). There have been other reports of the association of rheumatoid arthritis with silicosis in which there is no conclusive evidence to show that the pneumoconiosis had been modified by the rheumatoid process.

As early as 1950 Colinet had described a case of rheumatoid arthritis developing in a young woman who suffered from severe silicosis, and although there was no evidence in his report of the silicosis having been modified by the rheumatoid disease, he later claimed (Colinet, 1953) that Caplan's researches had confirmed his view regarding an association between the two diseases. Martin and Fallet (1953) and Tara and others (1954) each describe cases of this simple association of the two diseases, and the latter authors record that Desse showed a similar case to the French Rheumatism League, maintaining that the association of the two diseases had been known for many years and in other times went by the name of the " maladie de Saint Roch."

The formation and evolution of the rheumatoid nodule have been the subject of many studies, and Collins (1937), Bennett, Zeller, and Bauer (1940), Gruenwald (1948), and Christie (1954) have given excellent descriptions of the histology of the granulomata. In the earlier lesions there appears to be a proliferation of collagenous tissue which soon undergoes a distinctive type of necrosis and around this central necrotic core develops a fibroblastic inflammatory response. In this inflamma- tory layer the fibroblasts are sometimes arranged in palisade form, large and small inflammatory cells are usually present, and newly formed capillaries are conspicuous. Collins (1937) concluded that the lesions were granulomata arising in tissues whose inflammatory reaction had been modified in an unknown manner, and Gruenwald (1948) later supported this view, maintaining that the lesion was the result of necrosis occurring in pre-formed granulation tissue. Christie (1954) also concurred in this view although maintaining that the special characters of the lesion were the consequence of such factors as the intensity, extent, duration, and localization of the action of the inflammatory process rather than of any unique attribute of the reacting tissue. Some workers have stressed the significance of vascular injury in the causation of necrosis in these lesions, Sokoloff (1953) and Kulka (1953), for example, maintaining that when necrosis occurred it did so in relation to the blood vessels in such a way as to suggest that some blood-borne necrotizing agent seeped out of the vessels into the surrounding tissues, finally affecting the walls of the vessel itself, which then became obstructed by thrombus. Bevans, Nadell, Demartini, and Ragan (1954) have suggested that the primary lesion is one of fibrinoid necrosis of vessel walls and that coalescence of several of these injured vessels and the inflammatory response resulted in a lesion indistinguishable from the rheumatoid nodule. The collagenous nature of the typical nodule has recently been studied by Kellgren (1952) and his associates by techniques employing $x$-ray diffraction patterns and electron microscopy. The results of these investigations have shown very clearly that the parts of a rheumatoid nodule which show the histological appearance of normal collagen show plenty of normal collagen fibrils by electron microscopy but give an $x$-ray diagram of more or less disorientated collagen, whereas in the parts that show advanced fibrinoid change the $x$-ray pattern typical of collagen may be entirely absent. The Schiff-positive nature of the fibrinoid material in these nodules suggests a polysaccharide component, a view which has received support from chemical analysis of the extracted material. It is Kellgren's opinion that the fibrinoid necrosis within the rheumatoid nodule is caused by destruction of the collagen-polysaccharide component of normal connective tissue, the collagen being removed but the polysaccharides remaining in an unusually insoluble form. Kellgren also points out that the disintegration of the collagen molecule is likely to lead to the liberation of a considerable number 
of peptides which may excite a peripheral fibroblastic reaction. In this way he suggests that the inflammatory reaction may occur as a response to the fibrinoid necrosis of collagen rather than, as is generally held, that the fibrinoid and other connective tissue changes result from the inflammatory reaction.

In discussing the pathogenesis of the necrobiotic lesions in coal-workers' pneumoconiosis, Gough and others (1955) considered it unlikely that the lesions represented an unusual reaction to the dust alone and tended to the view that the necrotic collagen of the pneumoconiotic nodule stimulated a particular type of inflammatory reaction in rheumatoid subjects. This view, which accepts the necessity for the presence of pre-formed collagen in the formation of the nodule, would account for the unusual frequency of the changes in coal-workers' pneumoconiosis and would also account for the appearance of the subcutaneous nodules over areas exposed to trauma. It would not, however, account for the appearance of widespread visceral necrobiotic lesions in some cases of rheumatoid arthritis unassociated with pneumoconiosis. In these cases, which are sometimes referred to as "malignant" rheumatoid disease, extensive necrobiotic lesions are present in areas where there is no evidence of pre-formed granulation tissue. It will be recalled that when a comparison between the distribution of nodular rheumatoid lesions in the pneumoconiotic and non-pneumoconiotic cases is made, a striking difference emerges between the two groups in that the nodules in the pneumoconiotic group are always confined to the lungs whereas the nodules in the non-pneumoconiotic group are never thus confined, the pulmonary lesions forming only a part of a widespread necrobiosis. It seems very unlikely that in these latter cases extensive areas of nodular collagen formation have preceded the necrobiotic nodules.

Finally, there remains to be discussed the part played by the silica particles themselves in the formation of the necrobiotic lesions. It may be significant in this connexion that there have as yet been no reports of the occurrence of rheumatoid hodules in lungs affected by non-pneumoconiotic fibrosis. If the presence of pre-existing fibrous tissue within the lungs were the principal determining factor in the occurrence of these lesions it is surprising that no such cases have as yet appeared. Apart from this negative evidence there are other features which suggest that the silica particles themselves may play an important role in the initiation of the necrobiotic changes, for not only is silica a necrotizing agent in its own right but a comparison of the structure of the nodules in our own case and those occurring in coal-workers' pneumoconiosis reveals a close similarity in histological structure, whereas the nature and distribution of the pulmonary fibrosis in the two diseases are widely different; in the case we record the presence of nodular rheumatoid lesions cannot be related to nodular masses of pre-formed collagen such as occur in silicosis.

For these reasons it appears to us that the weight of evidence does not suggest that preformed fibrous tissue is an invariable prerequisite for the formation of the nodular lesions, and that their appearance may be explained by assuming that some stimulus initiates necrobiotic changes in certain mesenchymal structures and that the necrosis in itself then excites a fibroblastic reaction in the manner suggested by Kellgren. It would also appear that the nature of the stimulus may vary according to the severity of the rheumatoid process and the distribution of lesions. In cases of "malignant rheumatoid disease" widespread necrobiosis may ensue without the intervention of any other physical or chemical agent, whereas in the more usual chronic forms of the disease an accessory factor appears necessary before necrobiosis is induced. In the more common subcutaneous lesions physical trauma itself would appear to be a sufficient stimulus whereas the chemical actions of dust particles may well be the exciting factor in the pneumoconiotic group of cases.

\section{SUMMARY}

A case of pulmonary asbestosis associated with rheumatoid lung changes is described. The lesions consisted of necrobiotic foci of histological structure similar to the more commonly encountered subcutaneous rheumatoid nodule. Previously published cases of the necrobiotic form of rheumatoid lung disease are reviewed and its curious association with pneumoconiosis is discussed. It is suggested that silica particles themselves may play a more important part than the presence of pre-formed collagen in the production of these lesions.

We are greatly indebted to Professor Gough for his original review of our case and for his kindness in supplying us with material from his own cases of Caplan's syndrome.

\section{A D D E N D U M}

Previously reported cases of non-pneumoconiotic lung disease in rheumatoid arthritis, with age and sex of patients: Bennett et al. (1940). M., 56 ; Bevans et al. (1954), F., 52, F., 46 ; Bloom and Rubin (1950), 
F., 26 ; Christie (1954), M., 57, M., 67, F., 57 ; Edge and Rickards (1957), M., 65, F., 52 ; Ellman (1947), age not stated, sex not stated ; Ellman (1956), M., 47, M., 29, M., 54, M., 59, M., 47 ; Ellman and Ball (1948), M., 47, F., 48, F., 55 ; Ellman and Cudkowicz (1954), F., 50, F., 58; Ellman, Cudkowicz, and Elwood (1954), M., 63 ; Ellman and Parkes Weber (1949), F., 34 ; Gruenwald (1948), M., 57 ; Harris (1954), M., 46 ; Katz and Auerbach (1951), M., 51 ; Leys and Swift (1949), M., 6 ; Middleton (1951), M., 48, M., 45 ; Price and Skelton (1956), F., 58 ; Raven, Weber, and Price (1948), F., 62 ; Rubin (1955), F., 49, F., 58, F., 46, F., 65 ; Schlesinger (1949), F., 3, M., 9/12 ; Skogrand (1956), M., 41, F., 43, M., 52 ; Spence (1955), M., 47, M., 29 ; Yardumian and Kleinerman (1949), F., 43.

\section{REFERENCES}

Bennett, G. A., Zeller, J. W., and Bauer, W. (1940). Arch. Path. (Chicago), 30, 70 .

Bevans, M., Nadell, J., Demartini, F., and Ragan, C. (1954). Amer. J. Med., 16, 197 .

Bloom, J., and Rubin, J. H. (1950). Canad. med. Ass. J., 63, 355.

Caplan, A. (1953). Thorax, 8, 29.

Christie, G. S. (1954). Aust. Ann. Med., 3, 49.
Colinet, E. (1950). Acta physiother. rheum. belg., 5, 185. (1953). Ibid. 8, 37.

Collins, D. H. (1937). J. Path. Bact., 45, 97.

Edge, J., and Rickards, A. G. (1957). Thorax, 12, 352.

Ellman, P. (1947). Proc. roy. Soc. Med., 40, 332.

(1956). Postgrad. med. J., 32, 370

and Ball, R. E. (1948). Brit. med. J., 2, 816.

and Cudkowicz, L. (1954). Thorax, 9, 46.

and Elwood, J. S. (1954). J. clin. Path., 7, 239

- and Parkes Weber, F. (1949). Brit. med. J., 1, 304

Gough, J., Rivers, D., and Seal, R. M. E. (1955). Thorax, $10,9$.

Gruenwald, P. (1948). Arch. Path. (Chicago), 46, 59.

Harris, L. H. (1954). Lancet, 2, 119.

Katz, H. L., and Auerbach, O.'(1951). Dis. Chest, 20, 366

Kellgren, J. H. (1952). Brit.med. J., 1, 1093 and 1152 .

Kulka, J. P. (1953). Lancet, 1, 1233.

Latham, P. M. (1845). Lectures on Clinical Medicine, Vol. 1, p. 85 London.

Leys, D. G., and Swift, P. N. (1949). Brit. med. J., 1, 434.

Martin, E., and Fallet, G. H. (1953). Schweiz.med. Wschr.,83, 776.

Meer, C. van der (1954). Ned. T. Geneesk., 98, 3539.

Miall, W. E., Caplan, A., Cochrane, A. L., Kilpatrick, G. S., and Oldham,P. D.(1953). Brit.med.J., $2,1231$.

Middleton, J. W. (1951). Dis. Chest 19,473.

Price, T. M. L., and Skelton, M. O. (1956). Thorax, 11, 234

Raven, R.W., Weber, F.P., and Price, L.W. (1948). Ann. rheum. Dis. 7,63 .

Rubin, E. H. (1955). Amer. J. Med., 19, 569.

Schlesinger, B. (1949). Brit. med. J., 2, 197.

Skogrand, A. (1956). Acta rheum. scand., 2, 17.

Sokoloff, L. (1953). Lancet, 1, 1232.

Spence, M. P. (1955). Arch. Middx Hosp., 5, 95.

Tara, S., Cavigneaux, A., and Delplace, Y. (1954). Arch. Mal. prof., $15,42$.

Yardumian, K., and Kleinerman, J. (1949). Arch.intern. Med., 83, 1 